\title{
Effect of Cold Rolling Path on the Deformation Textures Of C10300 Copper
}

\author{
Caio Rodrigues de Souza ${ }^{a, b}$, Eduardo Franco de Monlevade ${ }^{b}$ (iD \\ ${ }^{a}$ Centro Paula Souza, São Paulo, SP, Brasil. \\ ${ }^{b}$ Escola Politécnica da Universidade de São Paulo, Departamento de Engenharia Metalúrgica e de \\ Materials, São Paulo, SP, Brasil.
}

Received: July 24, 2020; Revised: December 2, 2020; Accepted: January 8, 2021

\begin{abstract}
Commercially free, $\mathrm{C} 10300$ Copper was submitted to cold rolling to $80 \%$ thickness reduction using three different rolling schedules. Rolling was conducted in 5, 8 and 11 rolling passes. Samples were then submitted to EBSD analysis at the surface and X-Ray Diffraction at the surface and mid-thickness to evaluate the deformation texture. EBSD analysis showed an increase in the intensity of the Copper component at the surface as the number of rolling passes decreased, and a very strong Goss component in all samples analyzed. X-ray diffraction analysis confirmed the strong copper component, but the Goss texture was much weaker when analyzed by X-ray diffraction, ultimately being nearly inexistent at mid thickness. The Brass component was very weak in EBSD analyses, but was found with higher intensity when texture was calculated using x-ray diffraction. The appearance of Goss component in surface grains can be explained by friction and shearing conditions in the roll-metal contact.
\end{abstract}

Keywords: Deformation texture, Cold rolling, Copper.

\section{Introduction}

Copper is one of oldest metals ever known to man. The ability to form copper and, later on, bronze, was fundamental to the early technological development of man. To this day, industrial applications of copper are countless, and a great percentage of these applications require that copper undergoes mechanical forming. It is well known that the textures that develop during deformation will play an important role in the textures that will be encountered after recrystallization and will also play an important role in further cold working. The strain path (sequence of deformation processes to which the metal is submitted) may have a strong effect on the deformation textures that develop during cold work, and also on the textures that emerge after recrystallization. This topic was addressed by McDonald et al. ${ }^{1}$, studying the influence of strain path on recrystallization of pure copper, including kinetics and texture. However, the authors do not focus on the development of deformation textures.

For example, studies conducted by Pan et al. ${ }^{2}$ indicated that the recrystallization texture of magnesium alloyed with zinc and gadolinium is altered when cross rolling (switching the rolling direction by a 90 degree rotation) is performed. The authors also indicate that planar anisotropy is absent when this method is employed.. Deng et al. ${ }^{3}$ studied the influence of rolling path on texture of high purity tantalum and reported that cross rolling led to a similar deformation texture as unidirectional rolling at the end of deformation. According to Deng et al., During Deformation, the evolution of deformation textures in unidirectional rolling (in high purity Tantalum) presents an increasing gamma fiber as deformation proceeds.

*e-mail: monlevade@usp.br
A much less complex strain variation condition is the one attained when the strain rate is changed within a same path, such as the changes caused by varying the cold rolling schedule. Although copper and brass were the metals first used for the development of knowledge regarding texture evolution, mostly because there are roughly any phase transitions purely dependent on temperature variation (as opposed to iron), strain rate dependence of textures in copper remains an open topic, with studies being conducted on texture evolution, microstructure evolution and mechanical properties. Also, the usual rolling textures are long known, with works already in the early 1900 s reporting textures components that would later be known as Copper and Brass. However, classic studies do not appear to take the reduction per pass under consideration. Parthasarathi and $\mathrm{Beck}^{4}$ reported that, as opposed to what is shown in early results, a (135)[21 $\overline{1}]$ type texture may result from cold rolling of copper, comparing it to a "Z texture" common in Nickel alloys.

Zandrahimi et al. ${ }^{5}$ studied the effect of strain path changes in several different cubic metals, including copper, indicating the consequences in strain hardening rates. However, texture development was not addressed. Battacharyya et al. ${ }^{6}$ reported a large strain rate sensitivity of Oxygen Free High Conductivity copper in simple shear tests, attributing it to differences in work hardening behavior (as indicated by Zandrahmini et al. ${ }^{5}$ ). The strain rate dependence of rolling texture was pointed out by Leffers ${ }^{7}$, in Copper- $5 \% \mathrm{Zn}$ alloy, indicating the tendency to Copper and Brass textures, and indicating that the selection of either texture is dictated by occurrence or not of cross-slip in the $\{111\}<\overline{1} 10>$ system. The most extensive work on this topic is that of Hirsch and Lucke $^{8}$ in which rolling at several degrees was conducted in order to evaluate the rolling texture evolution as deformation 
proceeds. Their work, however, did not use varying strain rates. The authors did, however, point out the existence of the $\alpha$-fiber (that is, $\{110\}$ planes parallel to the sheet surface) and $\beta$-fiber $(<110>$ direction tilted 60 degrees towards the rolling direction). The authors also indicate that rolling textures tend to scatter from the fibers as deformation proceeds, and do not indicate dominant components for high rolling reductions.

\section{Experimental Procedures}

Copper strips in cold rolled and annealed condition were used in this study. The initial thickness of the copper strip was $2.5 \mathrm{~mm}$. Small strips $25 \mathrm{~mm}$ wide were cut from the as received material and submitted to cold rolling with a final thickness reduction of $80 \%$, thus achieving a final thickness of $0.5 \mathrm{~mm}$. The final thickness was chosen in such a way that there would be enough material inside the bakelite mount to avoid distortion during preparation, and also to allow for surface and mid-thickness analysis.

Three rolling schedules were designed, with 5, 8 and 11 rolling passes. The samples were labeled AM00 (as received), AM01, AM02 and AM03. The theoretical reduction for each rolling pass was calculated using the real strain $\varepsilon$ in its logarithmic form. The calculation procedure consists of calculating $\varepsilon$ for the overall reduction and then dividing it by the number of rolling passes. Once the $\varepsilon$ per pass has been calculated, a backward calculation can be done to determine the thickness reduction. The theoretical reductions per pass are $27.5 \%$ ( 5 passes), $18.2 \%$ ( 8 passes) and $13.6 \%$ (11 passes). The calculated reductions and real reductions achieved are given in Tables 1 and 2. Although several attempts of cold rolling were made, only the ones that reached similar final thicknesses for each reduction were used. Deformed samples were submitted to X-Ray diffraction analysis for texture determination at the surface and mid-thickness.

Samples were submitted to standard metallographic preparation for observation at optical and scanning electron microscopes. Samples used for mid-thickness analysis were submitted to grinding after mounting. The initial thickness of the bakelite was measured using a caliper, and final thickness was controlled during grinding. For X-ray diffraction, the samples were polished down to 3 micrometer diamond paste. Electrolytic Etching for metallographic observation was done using a $30 \%$ Nital solution, with an applied voltage of $30 \mathrm{~V}$ and a current of $2.6 \mathrm{~A}$, for 30 seconds. X-Ray diffraction analysis was done in a Rigaku Diffractometer equipped with a Chromium X-ray tube and a texture goniometer. The X-ray diffraction was done using $\mathrm{Cr}-\mathrm{K} \alpha$ radiation.

The data acquisition using the texture goniometer was done using a 5 degree rotation step, ranging from -75 to 75 degrees with the horizontal plane. Pole figures for (220), (111), (200) and (311) planes were acquired and used for ODF construction. The ODFs were constructed using a software developed at the Brazilian Institute of Energy and Nuclear Research (Instituto de Pesquisas Energéticas e Nucleares - IPEN). Deformed samples were submitted to EBSD analyses to evaluate the deformation texture as well. The EBSD analysis is very sensitive to deformation. To overcome this limitation, the deformed samples were submitted to a recovery heat treatment at $300^{\circ} \mathrm{C}$ for 1 hour. In this way, dislocation annihilation is induced, yielding a less deformed structure for analysis without, however, destroying the deformation structure and deformation textures. For the EBSD analyses, samples were submitted to final polishing (after standard metallographic preparation) in $0.025 \mathrm{~mm}$ colloidal silica suspension in a Buehler Minimet ${ }^{\circledR}$ polisher, with an applied load of $1 \mathrm{~N}$ and $15 \mathrm{rpm}$. No etching was performed. The EBSD analyses were performed in a FEI Inspect 50 FEG Scanning Electron microscope with a TSL-EDAX EBSD system. The acceleration voltage used was $20 \mathrm{kV}$ and a 1 micrometer step was used.

Tables 3 and 4 contain the reading of the main texture components found, referred to by numbers, and these numbers are overlaid to the ODFs to help the interpretation. Table 3 refers to EBSD analyses and Table 4 refers to XRD analyses. The EBSD software allows for exact angle and intensity reading in the ODF due to a software functionality. However, the software used to calculate de ODFs from XRD analyses does not allow for that direct reading. Therefore, the approximate intensities of texture components in the XRD analyses are based on the intensity level curves.

\section{Results and Discussion}

The microstructures of the as received and as rolled materials are shown in Figure 1. Apart from the obvious elongation of grains in deformed samples, no significant differences were observed between different reduction sequences. The etchant used did not reveal any difference in

Table 1. Calculated reduction sequences for 5,8 and 11 rolling passes

\begin{tabular}{cccc}
\hline Sample & $\begin{array}{c}\text { Rolling } \\
\text { passes }\end{array}$ & Reduction Sequence $(\mathrm{mm})$ \\
\hline AM01 & 5 & $2.50 \longrightarrow 1.81 \longrightarrow 1.31 \longrightarrow 0.95 \longrightarrow 0.69 \longrightarrow 0.50$ \\
\hline AM02 & 8 & $2.50 \longrightarrow 2.04 \longrightarrow 1.67 \longrightarrow 1.37 \longrightarrow 1.12 \longrightarrow 0.91 \longrightarrow 0.75 \longrightarrow 0.61 \longrightarrow 0.50$ \\
\hline AM03 & 11 & $2.50 \longrightarrow 2.16 \longrightarrow 1.87 \longrightarrow 1.61 \longrightarrow 1.39 \longrightarrow 1.20 \longrightarrow 1.04 \longrightarrow 0.90 \longrightarrow 0.78 \longrightarrow 0.67 \longrightarrow 0.58 \longrightarrow 0.50$ \\
\hline
\end{tabular}

Table 2. Real reduction sequences for 5, 8 and 11 rolling passes

\begin{tabular}{cccc}
\hline Sample & $\begin{array}{c}\text { Rolling } \\
\text { passes }\end{array}$ & Reduction Sequence $(\mathrm{mm})$ \\
\hline AM01 & 5 & $2.50 \longrightarrow 1.96 \longrightarrow 1.20 \longrightarrow 0.92 \longrightarrow 0.72 \longrightarrow 0.49$ \\
\hline AM02 & 8 & $2.50 \longrightarrow 2.20 \longrightarrow 1.79 \longrightarrow 1.44 \longrightarrow 1.09 \longrightarrow 0.95 \longrightarrow 0.81 \longrightarrow 0.64 \longrightarrow 0.49$ \\
\hline AM03 & 11 & $2.50 \longrightarrow 2.33 \longrightarrow 2.10 \longrightarrow 1.39 \longrightarrow 1.36 \longrightarrow 1.13 \longrightarrow 0.99 \longrightarrow 0.88 \longrightarrow 0.77 \longrightarrow 0.69 \longrightarrow 0.57 \longrightarrow 0.49$ \\
\hline
\end{tabular}


Table 3. Texture components encountered in the as received material and deformed samples in EBSD analyses (components identified in the $45^{\circ}$ cut). The index is overlaid to the ODF cuts in Figures 3, 4 and 5.

\begin{tabular}{|c|c|c|c|c|c|c|c|}
\hline Sample & Index & Component & Intensity & $\phi_{1}$ & $\varphi$ & $\phi_{2}$ & Usual \\
\hline \multirow{4}{*}{ AM00 } & 1 & $(112)\left[\begin{array}{ll}-1-1 & 1\end{array}\right]$ & 6.3 & $89.5^{\circ}$ & $35.1^{\circ}$ & $45^{\circ}$ & Copper \\
\hline & 2 & $(110)\left[\begin{array}{lll}0 & 0 & 1\end{array}\right]$ & 0.6 & $89.9^{\circ}$ & $89.3^{\circ}$ & $45^{\circ}$ & Goss \\
\hline & 3 & $(001)\left[\begin{array}{ll}1-1 & 0\end{array}\right]$ & 2.6 & $0.3^{\circ}$ & $0^{\circ}$ & $45^{\circ}$ & \\
\hline & 4 & $(001)\left[\begin{array}{ll}-1-1 & 0\end{array}\right]$ & 2.7 & $90^{\circ}$ & $0^{\circ}$ & $45^{\circ}$ & \\
\hline \multirow{4}{*}{ AM01 } & 1 & $(112)\left[\begin{array}{ll}-1-1 & 1\end{array}\right]$ & 20.2 & $88.9^{\circ}$ & $33.7^{\circ}$ & $45^{\circ}$ & Copper \\
\hline & 2 & $(110)\left[\begin{array}{lll}0 & 0 & 1\end{array}\right]$ & 12.2 & $89.2^{\circ}$ & $90^{\circ}$ & $45^{\circ}$ & Goss \\
\hline & 5 & $(110)\left[\begin{array}{ll}1-1 & 2\end{array}\right]$ & 4.1 & $35.1^{\circ}$ & $89.2^{\circ}$ & $45^{\circ}$ & Brass \\
\hline & 3 & $(001)\left[\begin{array}{ll}1-1 & 0\end{array}\right]$ & 1.5 & $0.4^{\circ}$ & $0.3^{\circ}$ & $45^{\circ}$ & \\
\hline \multirow{3}{*}{ AM02 } & 1 & $(112)\left[\begin{array}{ll}-1-1 & 1\end{array}\right]$ & 17.7 & $90^{\circ}$ & $34.8^{\circ}$ & $45^{\circ}$ & Copper \\
\hline & 2 & $(110)\left[\begin{array}{lll}0 & 0 & 1\end{array}\right]$ & 18.5 & $89^{\circ}$ & $89.9^{\circ}$ & $45^{\circ}$ & Goss \\
\hline & 5 & $(110)\left[\begin{array}{ll}1-1 & 2\end{array}\right]$ & 1.8 & $35.1^{\circ}$ & $88.1^{\circ}$ & $45^{\circ}$ & Brass \\
\hline \multirow{3}{*}{ AM03 } & 1 & $(112)\left[\begin{array}{lll}-1-1 & 1\end{array}\right]$ & 3.6 & $90^{\circ}$ & $33.3^{\circ}$ & $45^{\circ}$ & Copper \\
\hline & 2 & $\left(\begin{array}{ll}110) \\
0\end{array}\left[\begin{array}{lll}0 & 0 & 1\end{array}\right]\right.$ & 7.2 & $89.9^{\circ}$ & $90^{\circ}$ & $45^{\circ}$ & Goss \\
\hline & 5 & $(110)\left[\begin{array}{ll}1-1 & 2\end{array}\right]$ & 3.1 & $36.1^{\circ}$ & $88.2^{\circ}$ & $45^{\circ}$ & Brass \\
\hline
\end{tabular}

Table 4. Main texture components found in the ODFs calculated from X-ray diffraction analysis in the $45^{\circ}$ cut. The index is overlaid to ODF cut in Figure 6.

\begin{tabular}{|c|c|c|c|c|}
\hline Sample & Index & Component & Intensity (approximate) & Classic component \\
\hline \multirow{4}{*}{ AM00 } & 1 & $(112)[-1-11]$ & 6.3 & Copper \\
\hline & 2 & $(110)\left[\begin{array}{lll}0 & 0 & 1\end{array}\right]$ & 0.6 & Goss \\
\hline & 3 & $(001)\left[\begin{array}{ll}1-1 & 0\end{array}\right]$ & 2.6 & \\
\hline & 4 & $(001)[-1-10]$ & 2.7 & \\
\hline \multirow{3}{*}{ AM01 } & 1 & $(112)[-1-11]$ & 16.3 & Copper \\
\hline & 2 & $(110)\left[\begin{array}{lll}0 & 0 & 1\end{array}\right]$ & 5.4 & Goss \\
\hline & 3 & $(110)[1-12]$ & 7.6 & Brass \\
\hline \multirow{3}{*}{ AM02 } & 1 & $(112)\left[\begin{array}{ll}-1-1 & 1\end{array}\right]$ & 16.0 & Copper \\
\hline & 2 & $(110)\left[\begin{array}{lll}0 & 0 & 1\end{array}\right]$ & 5.3 & Goss \\
\hline & 5 & $(110)\left[\begin{array}{ll}1-1 & 2\end{array}\right]$ & 7.1 & Brass \\
\hline \multirow{3}{*}{ AM03 } & 1 & $(112)[-1-11]$ & 16.7 & Copper \\
\hline & 2 & $(110)\left[\begin{array}{lll}0 & 0 & 1\end{array}\right]$ & 3.7 & Goss \\
\hline & 5 & $(110)[1-12]$ & 7.4 & Brass \\
\hline
\end{tabular}

shear bands, or deformation bands. The as received sample had a grain size of roughly 60-70 micrometers.

\subsection{EBSD Analyses}

The orientation mapping of the as received material and deformed samples are shown in Figure 2. The as received sample does not present a clear greater population of any particular orientation. It is clear that there is a tendency towards a greater population of green grains $(\{110\}$ parallel to the surface) as the number of reduction passes increases, and a greater population of purple to blue grains (towards $\{211\}$ parallel to the surface) as the number of passes decreases. The orientation distribution functions of all four samples are given in Figure 3. Only the 45, 60 and 90 degrees sections are shown here. A comparison of the ODF sections reveals that the Copper component is significantly stronger in the sample with the least reduction passes, and is much more intense than all other texture components observed in any other sample, with a peak of over 20 times random. The sample with 11 passes has a predominant Goss deformation texture, but still nearly $1 / 3$ as strong as the Copper textures observed in the sample submitted to 5 passes. The $45^{\circ}$ section of the ODFs of all 4 samples are shown in Figure 4. The predominant texture components found are numbered, and texture components found in each sample, including the as received material, are shown in Table 3. Upon deformation, the Brass component, which was absent in the as received material, was induced and is observed with an intensity of about 3-4 times random in all deformed samples, which is in good agreement with classic results. As the number of rolling passes increases, it is noticeable in the ODF that the Brass component becomes stronger and the Goss component becomes weaker, eventually reaching a very similar intensity for 11 rolling passes. In that sample, the Copper component has its intensity reduced to only a third of that found in the sample rolled in 5 passes.

\subsection{X-ray diffraction}

The ODFs of deformed samples calculated from x-ray diffraction at the sample surface data are shown in Figure 5. Although several of the components are the same, it is clear that the maximum intensities are very similar between samples, as opposed to what is observed when obtaining the ODFs from EBSD. The maximum intensities in EBSD calculated 

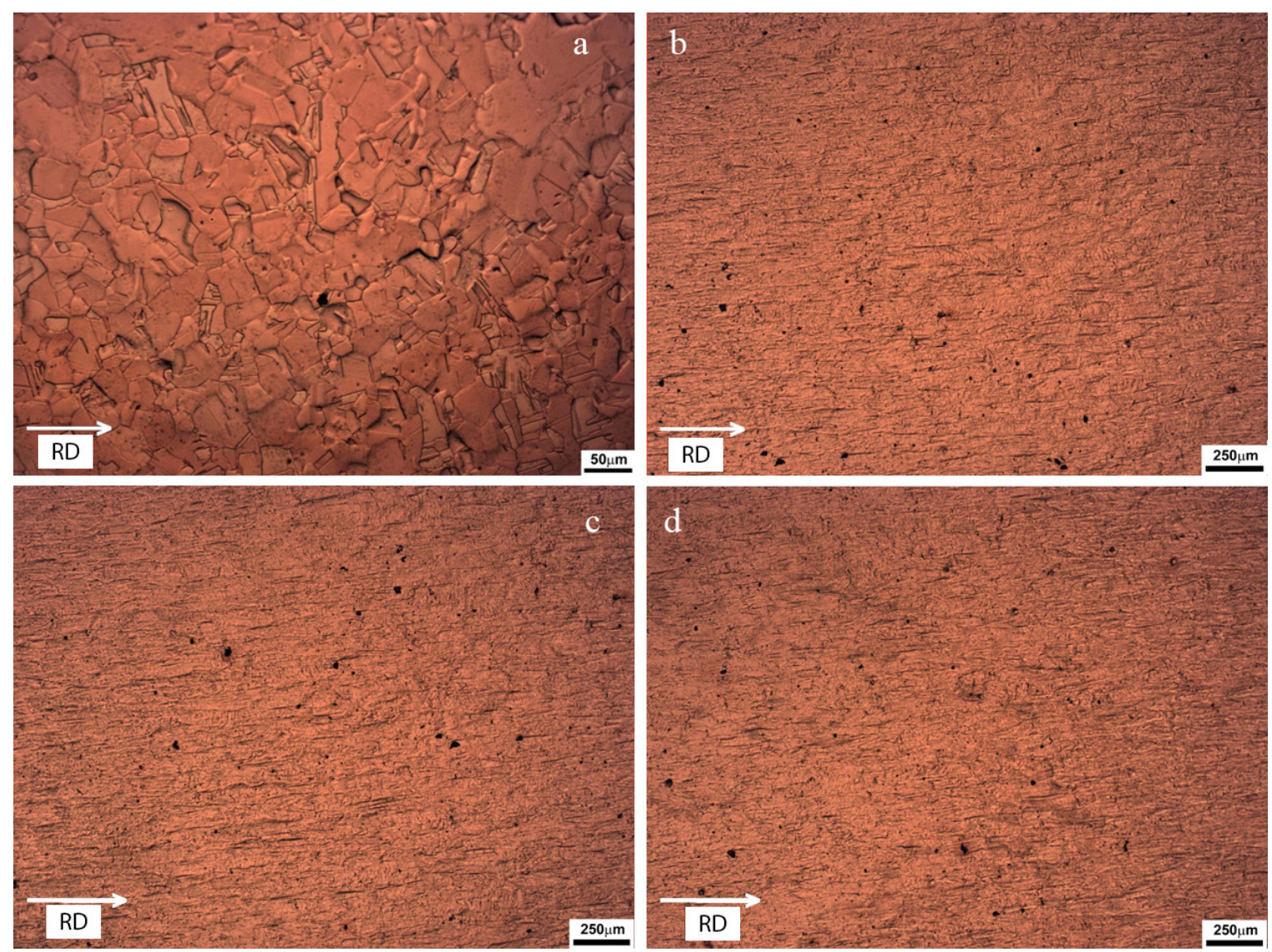

Figure 1. As deformed microstructures of samples a) As received b) AM01 (5 passes); c) AM02 (8 passes) and d) AM03 (11 passes) $(\mathrm{DL}=\mathrm{RD}-$ rolling direction)

ODFs, however, are extremely different, with sample AM01 (5 passes) showing a maximum texture intensity of 29 times random, in the Copper component, while the maximum intensity of all three samples was 17.3 times random, observed in sample 3 (11 passes), again in the Copper component. The reasons for that are related to the techniques themselves. While X-ray diffraction analyses a few thousand grains from a greater depth within the sample, EBSD is strictly restricted to the sample surface. The differences themselves are due to different conditions at the surface because of friction between the metal and the rolls, as well as a more intense shearing in that region. The XRD results (shown in Figure 5, with ODF sections of 45, 60 and 90 degrees), also do not show a strong Goss component in any of the samples, although it does take part in the alpha fiber and is present in weaker intensities in all samples, indicating that its significant appearance in the EBSD results is evidence that contact conditions between the rolls and the sample leads to very different shearing conditions at the surface, enough to induce different texture components. The " $Z$ " texture, indicated by Parthasarathi and Beck, is absent or very weak.

The ODFs taken from mid-thickness using X-ray diffraction are shown in Figure 6. Again, the texture components encountered are the same, but the maximum intensities vary over a wider range, from 13 to 17 times random, while all the analyses from the surface yielded maximum intensities close to 16 . The Goss component is much weaker, and almost completely absent in sample AM03, submitted to 11 reduction passes. Mid-thickness results are in greater agreement with the classic rolling texture results, for example, those of $95 \%$ cold worked copper reported by Hutchinson and Ray 9 , 50\% and 90\% reduction reported by Heidelbach et al. ${ }^{10}$. According to these authors, Goss and Brass components are usual deformation textures in cold worked copper, as both are part of the $\alpha$ fiber. Copper and $S$ textures, part of the $\beta$ fiber, are also common deformation textures in copper ${ }^{11}$. In fact, the strongest components found in this study are Copper components.

\section{Discussion}

The appearance of a strong Goss component in the EBSD analysis, in itself, is not in disagreement with the well-established results ${ }^{9-11}$, as that particular texture is part of the alpha fiber and therefore expected to develop. However, its great prominence, especially in the sample submitted to the least rolling passes, does call attention, indicating that severe deformation conditions during rolling may lead to the development of a predominant Goss texture in copper. Studies on severe plastic deformation of copper using Equal Channel Angular Extrusion (ECAE) did not show the significant appearance of the Goss 

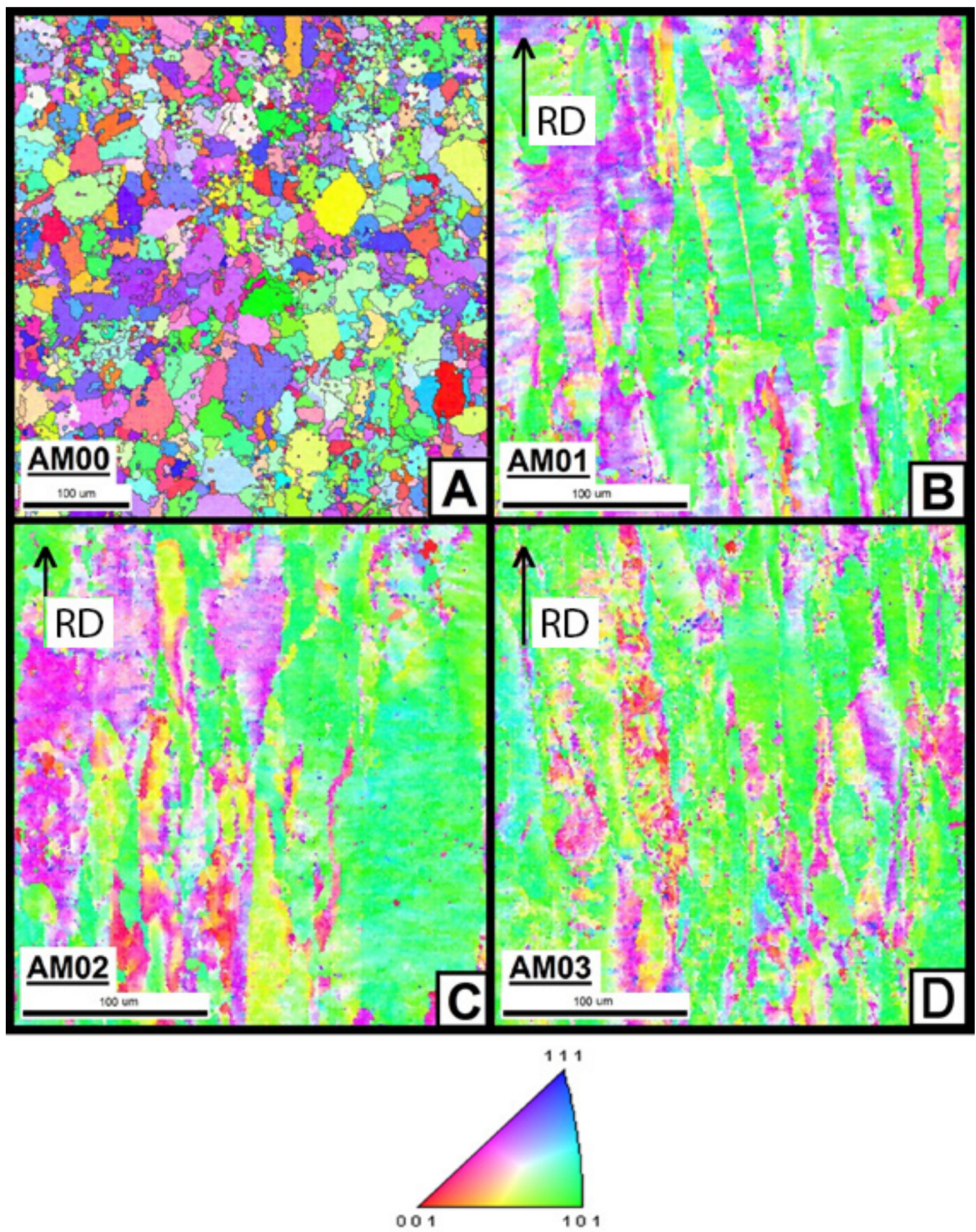

Figure 2. Orientation mapping of as received material and after cold rolling and recovery.

texture $^{12}$. Nevertheless, the deformation geometry in that technique is very different from what is observed in cold rolling. An interesting study is presented by Mao et al. ${ }^{13}$ reports the texture evolution in copper submitted to ECAE followed by cold rolling, compared to simple cold rolling. Mao et al.'s study focuses on recrystallization processes, but some important information may be gathered from the deformed state. According to the authors, the severe plastic deformation induced by ECAE heavily influences the texture evolution during recrystallization due to microstructural refining that takes place. The maximum intensity found in (111) pole figures is higher in cold 


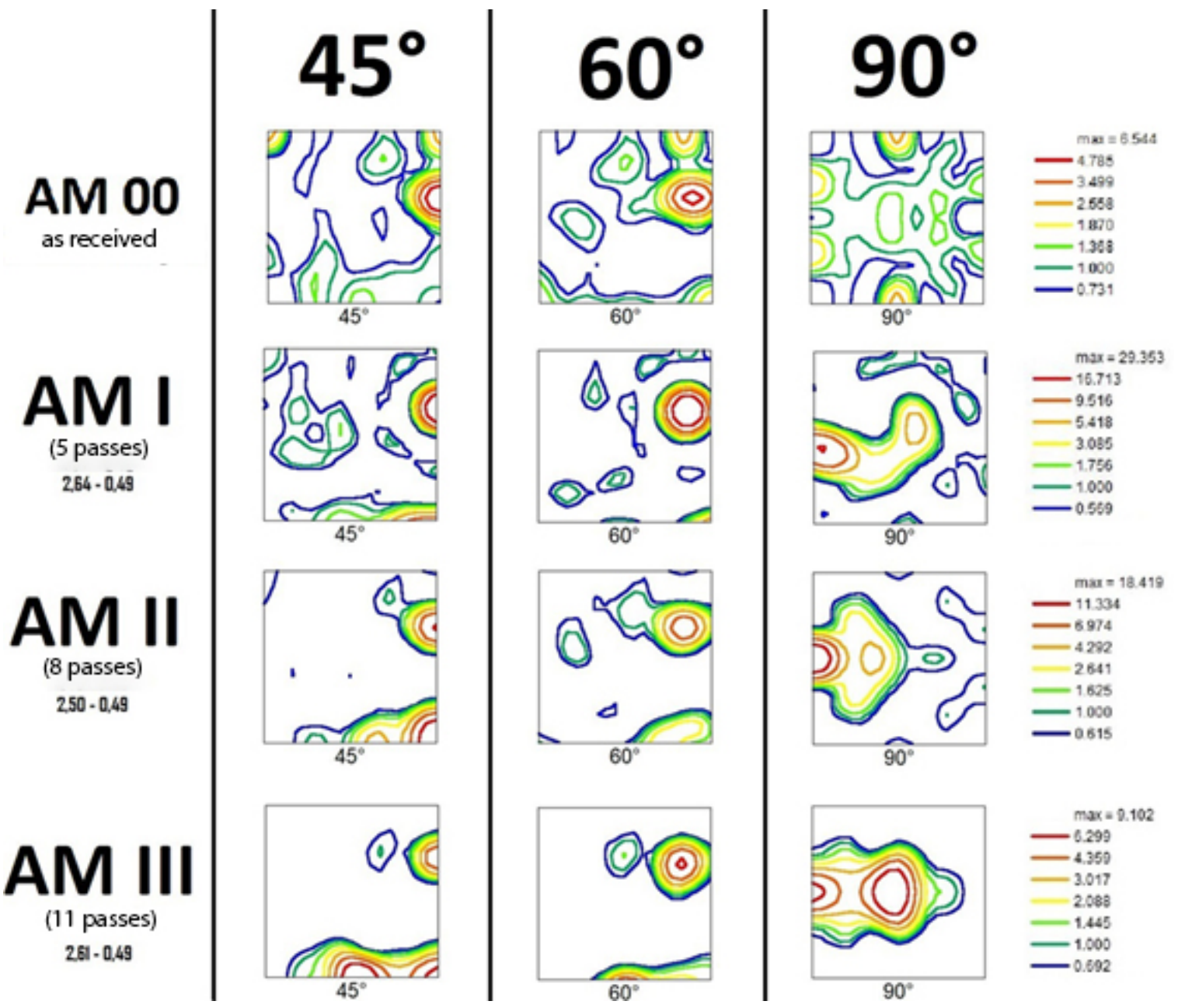

Figure 3. - 45, 60 and 90 degrees sections of the ODFs of all 4 samples.

AM00

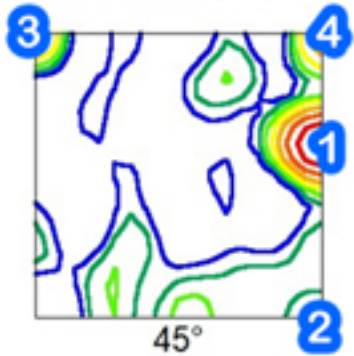

AM01

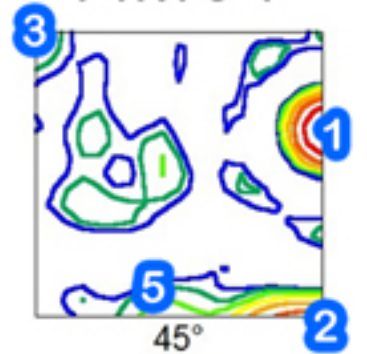

AM02

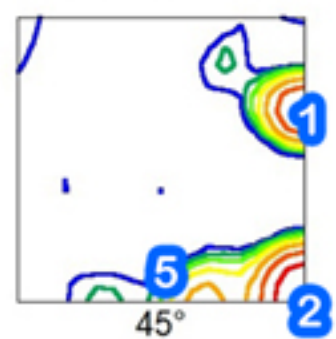

AM03

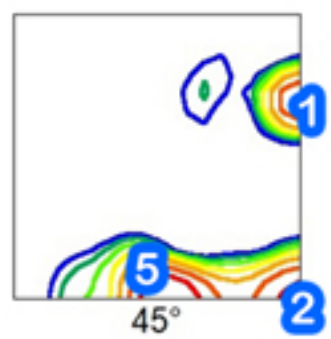

Figure 4. 45 degree section of the ODF from as received materials and deformed samples, indicating the texture components identified.

rolled copper, indicating that deformation textures are probably very differently distributed after the severe plastic deformation process. Basu et al. ${ }^{14}$, studying Surface Mechanical Attrition Treatment (SMAT) of pure copper, were able to detect texture differences between surface and sub-surface regions. At the surface, the ODF presented for the surface region shows the development of textures in the $\alpha$ fiber (including Goss, that can be inferred from the inverse pole figure presented by the authors), and a strong (111) component within a millimeter below the surface. At shallow depths, the $\alpha$ fiber components are still encountered, with different intensities. The $\alpha$ components near the surface (and the diminishing intensities as depth increases) are in good agreement with the result presented in this study, despite the difference in deformation severity. However, the strong (111) component was not found here. Again, deformation severity and geometry are very different between processes. 
a

EBSD
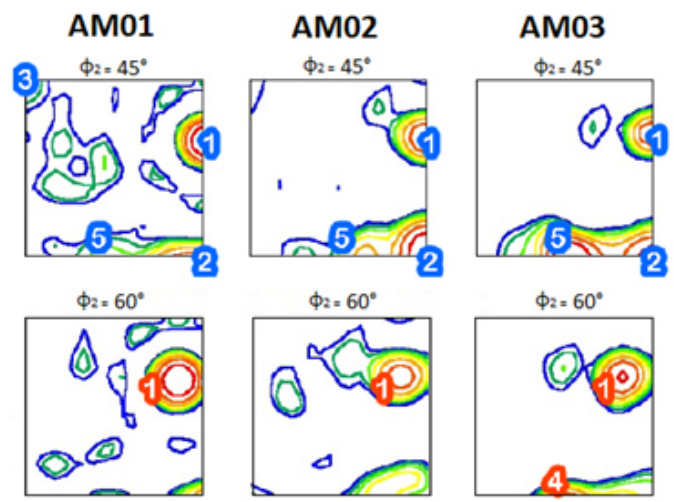

$\phi_{2}=90^{\circ}$
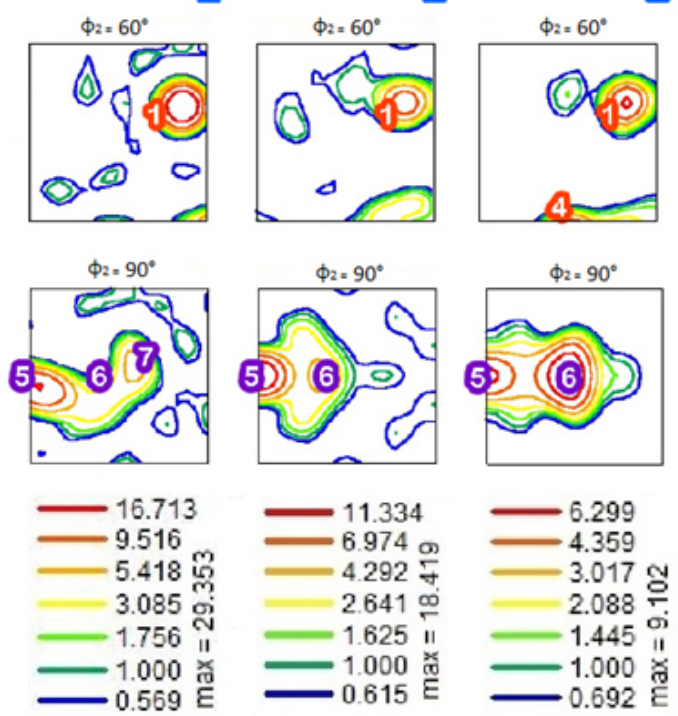
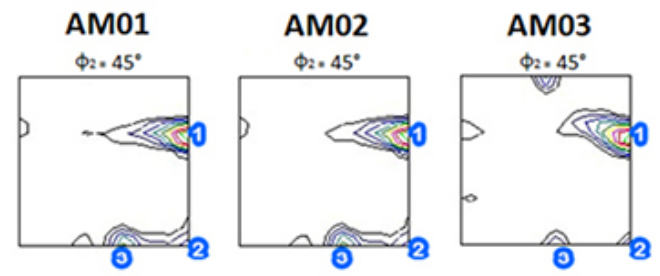

\section{X-ray Diffraction}
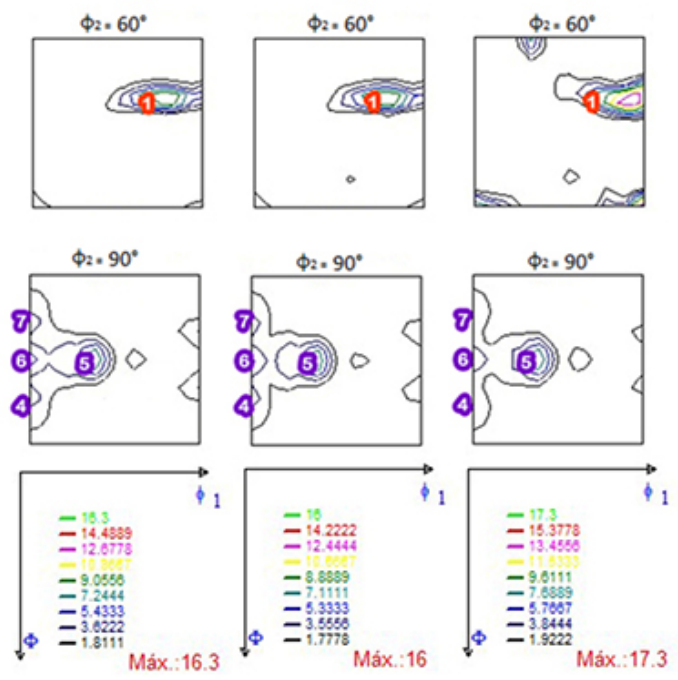

Figure 5. Comparison of ODFs obtained from EBSD analysis and X-ray diffraction at sample surface.

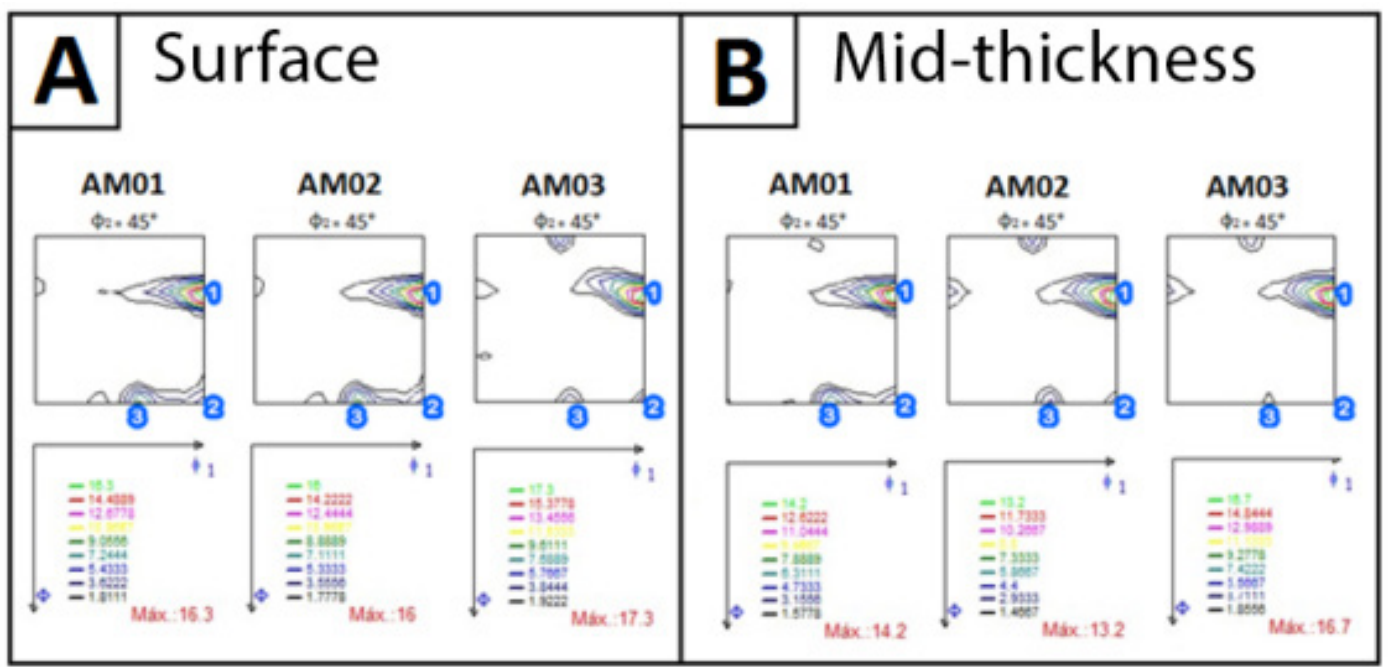

Figure 6. $45^{\circ}$ section of ODFs of samples AM01, AM02 and AM03 obtained from X-ray diffraction; a) surface; b) mid-thickness.

\section{Conclusions}

The change in rolling schedule, corresponding to varying strain rates in commercially pure copper, caused changes in the intensities of deformation texture components. At the surface itself, analyzed by EBSD, the Goss component is significantly strong, especially for fewer rolling passes. The copper component is the strongest texture in all conditions (rolling schedule and depth), and remarkably strong at the surface of the sample rolled in 5 passes. Towards the mid-thickness of the sample, the Goss component weakens 
considerably, ultimately being almost entirely absent for the mid-thickness of the sample rolled in 11 passes. The observed deformation textures are in good agreement with results reported in the literature for cold worked copper. Comparison with severe plastic deformation processes such as ECAP does not show such good agreement. This is probably due to differences in process geometry and in the intensity of deformation.

\section{Acknowledgements}

The authors are grateful to Dr. Nelson Batista de Lima, at IPEN (Instituto de Pesquisas Energéticas e Nucleares) for performing the X-ray analyses and providing the software for ODF construction from XRD data.

\section{References}

1. McDonald DT, Bate PS, Hutchinson WB. Effect of strain path change on recrystallisation in copper. Mater Sci Technol. 2005;21(6):693-700.

2. Pan S, Xin Y, Huang G, Li Q, Guo F, Liu Q. Tailoring the texture and mechanical anisotropy of a $\mathrm{Mg}-2 \mathrm{Zn}-2 \mathrm{Gd}$ plate by varying the rolling path. Mater Sci Eng A. 2016;653:93-8.

3. Deng C, Liu SF, Ji JL, Hao XB, Zhang ZQ, Liu Q. Texture evolution of high purity tantalum under different rolling paths. J Mater Process Technol. 2014;214:462-9.

4. Parthasarathi MN, Beck PA. Interpretation of Rolling Textures of copper. Trans Met Soc AIME. 1961;221:461-3.
5. Zandrahimi M, Platias S, Price D, Barrett D, Bate PS, Roberts WT. Effects of changes in strain path on work hardening in cubic metals. Metall Trans. 1989;20A:2471-82.

6. Bhattacharyya A, Rittel D, Ravichandran G. Effect of strain rate on deformation texture in OFHC copper. Scr Mater. 2005;52:657-61.

7. Leffers T. Deformation rate dependence of rolling texture in brass containing 5\% zinc. Scr Metall. 1968;2:447-52.

8. Hirsch J, Lücke K. Overview no. 76: mechanism of deformation and development of rolling textures in polycrystalline f.c.c. metals-I. Description of rolling texture development in homogeneous CuZn alloys. Acta Metall. 1988;36:2863-82.

9. Hutchinson WB, Ray RK. Influence of phosphorus additions in annealing behavior of cold-worked copper. Met Sci. 1979;13(34):125-30.

10. Heidelbach F, Wenk H-R, Chen SR, Pospiech J, Wright SI. Orientation and misorientation characteristics of annealed, rolled and recrystallized copper. Mater Sci Eng A. 1996;215:39-49.

11. Hong S-H, Lee DN. The evolution of the cube recrystallization texture in cold rolled copper sheets. Mater Sci Eng A. 2003;351:133-47.

12. Dalla Torre FH, Gazder AA, Pereloma EV, Davies CHJ. Recent progress on the study of the microstructure and mechanical properties of ECAE copper. J Mater Sci. 2007;42:1622-37.

13. Mao ZN, Gu RC, Liu F, Liu Y, Liao XZ, Wang JT. Effect of equal channel angular pressing on the thermal-annealing-induced microstructure and texture evolution of cold-rolled copper. Mater Sci Eng A. 2016;674:186-92.

14. Basu S, Wang Z, Saldana C. Deformation heterogeneity and texture in surface severe plastic deformation of copper. Proc. R. Soc. A. 2016;472:20150486. 